\title{
Optimization of Temperature Sensors for Drying Mangosteen Peel
}

\author{
Thadchapong Pongsuttiyakorn, ${ }^{1}$ Pitikhate Sooraksa, ${ }^{2 *}$ and Pimpen Pornchalermpong ${ }^{1}$ \\ ${ }^{1}$ Department of Food Engineering, School of Engineering, King Mongkut's Institute of Technology Ladkrabang, \\ 1 Chalongkrung, Ladkrabang, Bangkok 10520, Thailand \\ ${ }^{2}$ Department of Computer Engineering, School of Engineering, King Mongkut's Institute of Technology \\ Ladkrabang, 1 Chalongkrung, Ladkrabang, Bangkok 10520, Thailand
}

(Received September 14, 2021; accepted November 22, 2021)

Keywords: temperature control, food quality, tracking indicators, drying process, dried mangosteen peel

This paper presents the design and implementation of temperature sensors for drying mangosteen peel. To enhance the performance of temperature sensors in the drying process, Kalman innovation sequences and natural tracking indicators are employed. The natural tracking indicators can be realized by setting the maximum possible product surface temperature limit (PSTL) as the tracking points. This is very useful for preventing the loss of quality of food products. The use of temperature sensors designed using the PSTL control system is optimal in the sense that the system is adaptively adjusted for faster tracking to the set points and less energy consumption. According to experiments using mangosteen peel as the test material, the dried peel has the desired food quality. This implies that the proposed paradigm can be applied to enhance the performance of temperature sensors.

\section{Introduction}

In the drying of food, hot air is applied by convection, which circulates around the surface of the product to remove moisture. Consequently, the dried product has reduced weight and volume, which affects packaging, handling, and delivery costs. ${ }^{(1-4)}$ In addition, temperature is the main factor affecting the quality of food products. The biological quality of food is sensitive to high temperatures, which cause changes in color, smell, taste, structure, and nutritional values. Hence, it is necessary to preserve the quality of dried food and maintain the natural characteristics of the material. ${ }^{(3-6)}$

The effects of the drying temperature on product quality are not fully understood. ${ }^{(6-10)}$ Research has been carried out on the development of automatic dryers to improve the quality of products. ${ }^{(11-14)}$ Controlling the drying chamber air temperature and the product surface temperature are important factors significantly affecting the quality of the dried product. ${ }^{(13,14)}$ In-depth research has been carried out on stratified temperature control profiles that change according to the process and conditions for each stage of drying. It has been demonstrated that the bio-quality of heat-sensitive products can be affected at high air temperatures during the first drying process. ${ }^{(14-17)}$

${ }^{*}$ Corresponding author: e-mail: pitikhate.so@kmitl.ac.th https://doi.org/10.18494/SAM.2021.3627 
In addition, another factor affecting the product in the drying process is the moisture content, which is essential in predicting the behavior of food during processing. ${ }^{(18-22)}$ The use of weight results to calculate the dry base moisture content is complicated and it is easy to make a mistake. To deal with this problem, a weight sensor is installed in both indoor and outdoor driers. ${ }^{(23-26)}$ Our previous work focused on improving the accuracy of weight measurements when temperature changes occurred during drying. ${ }^{(27)}$

To extend the results of Ref. 27, product surface temperature limits (PSTLs) are used as food quality controls and as criteria for ending the drying process to maintain the required weight. ${ }^{(27)}$ In this process, a time constant is employed to impose a rule for assigning the gain condition. The recursive least squares (RLS) algorithm is used to update an innovative sequence that provides suitable control gains for the drying process to achieve the desired efficiency and satisfactory quality of the final product.

\section{Materials and Methods}

\subsection{Set-point scheduling using time constant}

The drying process can be mathematically considered as a first-order system. In practice, we can linearize the input heat power and set a constant fan speed for each time constant. The set point of the food surface at temperature $T$ is assigned a corresponding time constant $\tau$ at each step, as shown in Fig. 1. This process can be mathematically described by

$$
\bar{T}=\left(T-T_{i}\right) /\left(T_{f}-T_{i}\right)=1-e^{(-t / \tau)},
$$

where $\bar{T}$ is the percentage response, $T$ is the temperature at time $t\left({ }^{\circ} \mathrm{C}\right), T_{i}$ is the initial temperature $\left({ }^{\circ} \mathrm{C}\right), T_{f}$ is the final temperature $\left({ }^{\circ} \mathrm{C}\right), t$ is the time, and $\tau$ is the time constant of the

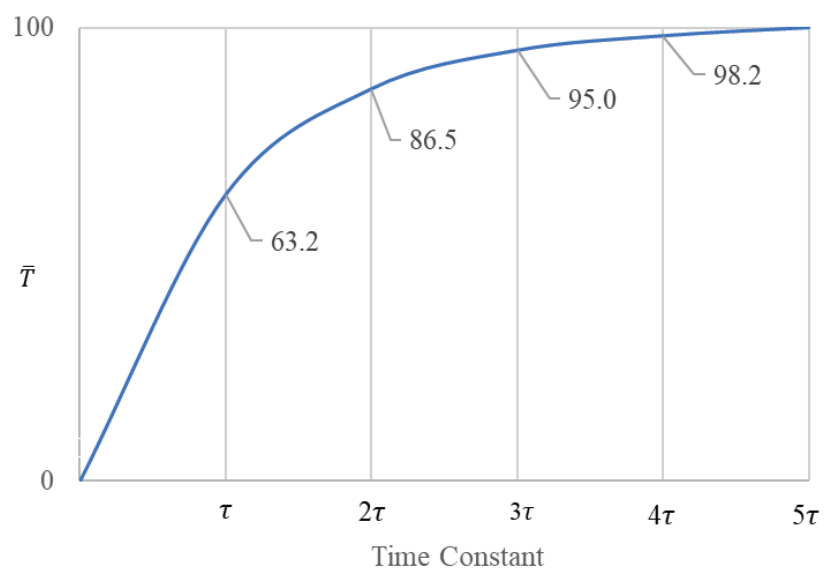

Fig. 1. (Color online) Natural tracking indicators specified by time constants. 
process. As can be seen from Fig. 1, the response curve is exponential. Between $t=0$ and time constant $\tau$, the response increases from 0 to $63.2 \%$ of the maximum limit surface temperature of the product. At time constant $2 \tau$, the response reaches $86.5 \%$ of the maximum limit. At $t=3 \tau$, $4 \tau$, and $5 \tau$, the response reaches $95,98.2$, and $99.3 \%$ of the maximum limit, respectively. In practice, to retain food quality, we can set the maximum limit surface temperature of the product at four time constants $(4 \tau)$. This is equal to reaching the $2 \%$ line of the maximum limit value in the steady state, which can be reasonably estimated as the response time to reach the target point.

In this study, a PC151MT-0 non-contact infrared temperature sensor (Calex Electronics Ltd., UK) is used to measure product surface temperatures. The sensor has an operating range of $0-250{ }^{\circ} \mathrm{C}$, an accuracy of $0.1 \pm 0.5^{\circ} \mathrm{C}$, a measuring range of $15: 1,24 \mathrm{~V}$ DC voltage, a current of 4-20 $\mathrm{mA}$, and two signaling wires.

\subsection{Control architecture and algorithms}

This section describes the control architecture and algorithm used to control the drying process. The RLS algorithm is employed, which has been demonstrated to be highly effective against noise and has long been used in control and communication engineering. ${ }^{(28,29)}$ The discrete time version of the standard RLS algorithm is as follows:

$$
\begin{gathered}
P(k+1)=[1 / \lambda(k+1)][P(k)-K(k+1)][P(k) \phi(k+1)]^{T} \\
\theta(k+1)=\theta(k)+K(k+1) \varepsilon(k+1) \\
\lambda(k+1)=\lambda_{0} \lambda(k)+\left(1-\lambda_{0}\right) \\
K(k+1)=[P(k) \phi(k+1)] /\left[\lambda(k+1)+\left[\phi^{T}(k+1) P(k) \phi(k+1)\right]\right] \\
\varepsilon(k+1)=y(k+1)-\phi^{T}(k+1) \theta(k)=\text { the innovation sequence, }
\end{gathered}
$$

where $k$ is the discrete time and $P, K, \theta, \lambda$, and $\varepsilon$ are the recursion following an algebraic Riccati equation, the Kalman gain, the parameter vector, the forgetting factor, and the innovation sequence, respectively. The RLS algorithm is used to obtain a process model to regulate the rules for the corresponding area of each constant in the drying process control to adjust the air temperature according to the increase in the product surface temperature. The overall control architecture and a flowchart for product surface temperature control and moisture content measurement while drying food are shown in Figs. 2 and 3, respectively. 


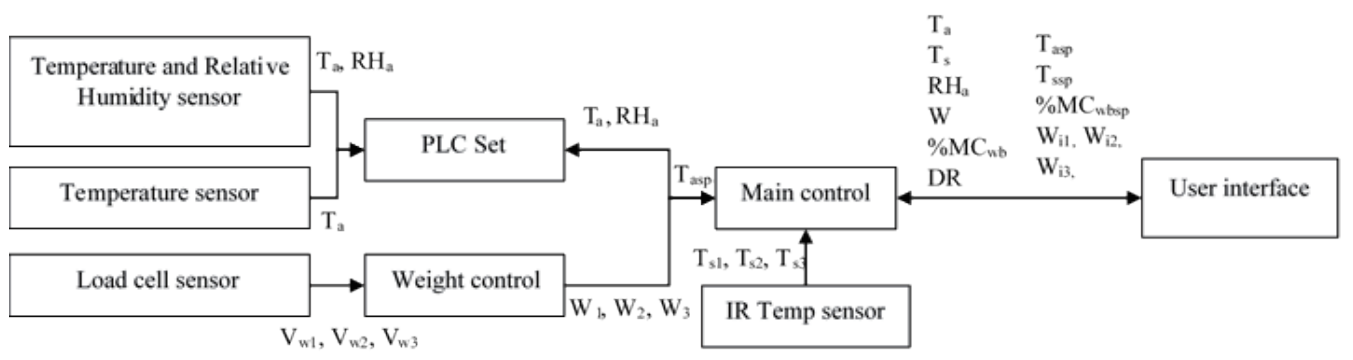

Fig. 2. Overall control architecture of the proposed drying process.

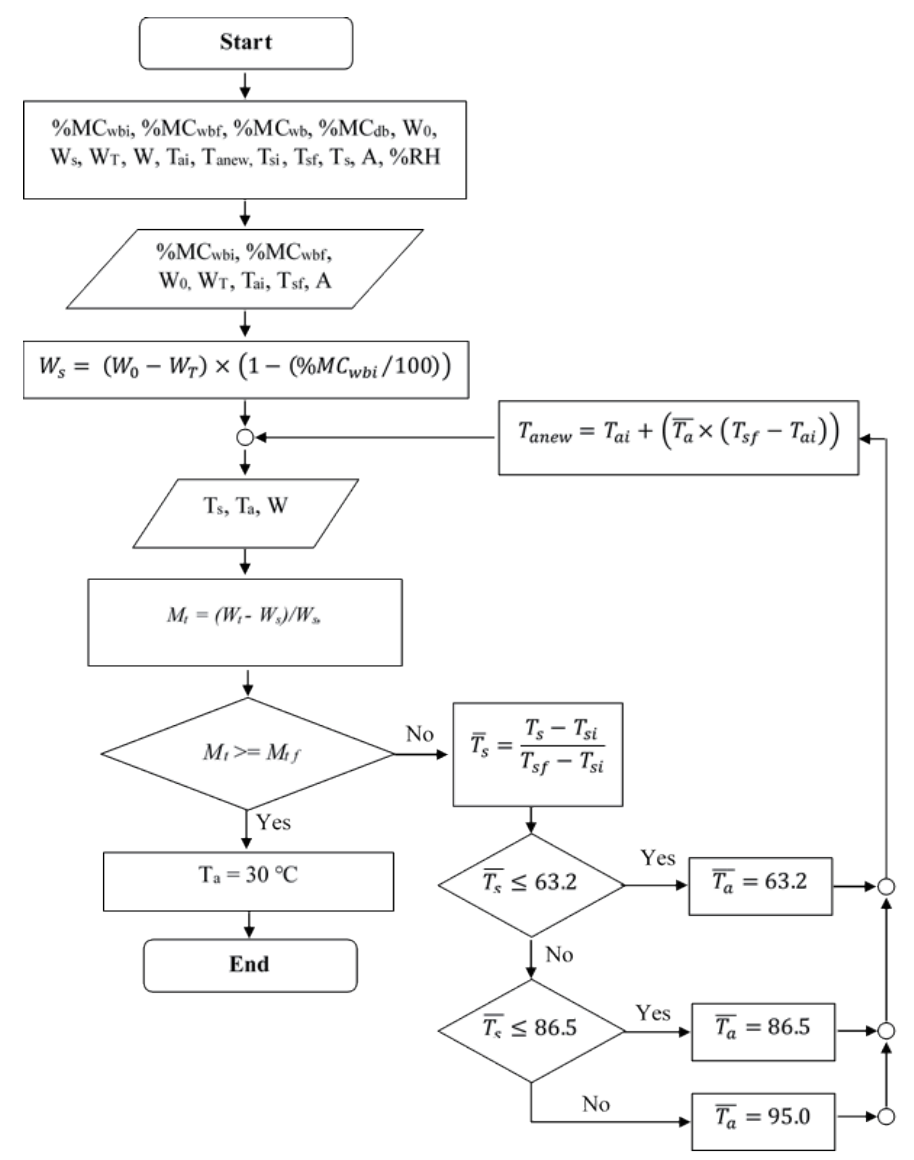

Fig. 3. Flowchart of product surface temperature control and moisture content measurement.

\subsection{Drying process}

\subsubsection{Moisture contents}

The moisture content was experimentally estimated using a $61022-3 \mathrm{KG}-0000 \mathrm{M}$ load cell sensor (Sensortronics, USA), which can measure a maximum weight of $3 \mathrm{~kg}$ and has a temperature range from 0 to $70{ }^{\circ} \mathrm{C}$ with a total output value of $3.0 \mathrm{mV} / \mathrm{V}$. To compensate for the drying temperature tolerance, ${ }^{(27)}$ we define $M_{t}$ as the sample moisture for each period (kg water/ 
$\mathrm{kg}$ dry solid), $W_{t}$ as the total weight of the sample for each period (kg), and $W_{s}$ as the solid weight of the sample $(\mathrm{kg})$. The equation of the sample's moisture content at each sampling time is

$$
M_{t}=\left(W_{t}-W_{s}\right) / W_{s} .
$$

\subsubsection{Drying rate}

To calculate the drying rate of the process, the mass of liquid evaporation per area per time is evaluated as

$$
R_{a}=-\left(W_{w} / A\right)(d m / d t),
$$

where $R_{a}$ is the drying rate $\left(\mathrm{kg} / \mathrm{m}^{2}\right), W_{w}$ is the water weight of the sample at time $k(\mathrm{~kg}), A$ is the water evaporation area (sq $\mathrm{m}$ ), and $d m / d t$ is the weight. Note that the evaporated water per unit time has the unit $\mathrm{kg} / \mathrm{h}$.

\subsection{Drying experiment}

\subsubsection{Mangosteen peel}

The mangosteen peel was coarsely blended and packed in a laminated bag with $2 \mathrm{~kg}$ of peel per bag, then frozen by blasting freezing air at $-38^{\circ} \mathrm{C}$ for $90 \mathrm{~min}$ and stored at $-18{ }^{\circ} \mathrm{C}$, as shown in Fig. 4. Before drying, the sample was thawed in a cabinet at $4{ }^{\circ} \mathrm{C}$ for $8 \mathrm{~h}$.

\subsubsection{Drying conditions}

To experimentally acquire suitable conditions for the drying process using mangosteen as the product, $300 \mathrm{~g}$ of the material was sorted on a sieve with none of the peel overlapping. The effects of drying temperatures of 50 and $60{ }^{\circ} \mathrm{C}$ with a wind speed of $1.3 \mathrm{~m} / \mathrm{s}$ were compared. The product was dried until the final wet base moisture reached $5 \%$ (the desired value). The starting

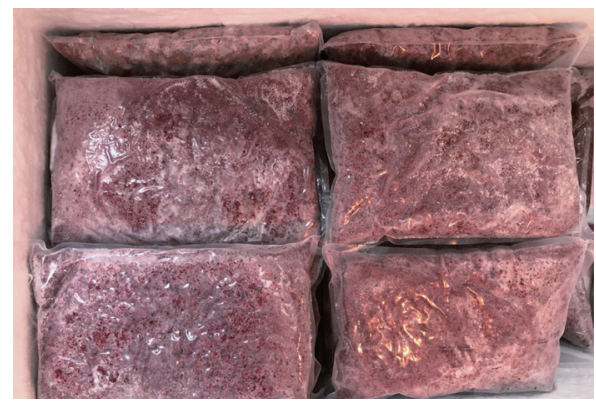

Fig. 4. (Color online) Frozen mangosteen peel. 
air temperature was set at $70{ }^{\circ} \mathrm{C}$. The air temperature, product surface temperature, and weight data were recorded every minute until the end of the process.

\subsubsection{Quality analysis}

The dried mangosteen peel was ground into powder with a dry food grinder and its moisture content, water activity, and color were analyzed as follows:

(1) Moisture content

The moisture content was determined by weighing the sample before and after drying and using Eq. (7). Approximately $2 \mathrm{~g}$ of dehydrated powdered mangosteen peel was first placed in a cup to determine its weight, then it was placed in an oven with an air temperature of $100{ }^{\circ} \mathrm{C}$ until the weight was stable. The weights of the sample pre-drying and post-drying were recorded using a four-digit decimal balance, then the moisture content was calculated using Eq. (7). This procedure was repeated three times and the average was taken.

(2) Water activity

Three samples of 3-5 g of powdered mangosteen peel were taken, and their water activity was measured with a water activity meter (Decagon Model, AquaLab, USA).

(3) Color

The color of the mangosteen peel was measured before and after drying with a color meter (ColorFlex, Hunter Lab, USA) using the CIE for the $L^{*}, a^{*}$, and $b^{*}$ color system. Equations (9) and (10) were used to calculate the hue angle and chroma value.

$$
\begin{gathered}
\text { Hue angle }= \begin{cases}\operatorname{arctangent}\left(b^{*} / a^{*}\right) & \text { when } a^{*}>0 \text { and } b^{*} \geq 0 \\
\operatorname{arctangent}\left(b^{*} / a^{*}\right)+180^{\circ} & \text { when } a^{*}<0 \\
\operatorname{arctangent}\left(b^{*} / a^{*}\right)+360^{\circ} & \text { when } a^{*}>0 \text { and } b^{*}<0\end{cases} \\
\text { Chroma }=\left(a^{\left.*^{2}+b^{* 2}\right)^{1 / 2}}\right.
\end{gathered}
$$

\subsubsection{Energy consumption}

The energy consumption in the drying process was analyzed by recording the power. Energy consumption and energy efficiency or specific energy consumption were calculated using Eqs. (11) and (12), respectively:

$$
E=P t
$$

$E$ : energy consumption $(\mathrm{kW} / \mathrm{h}), P$ : electric power $(\mathrm{kW}), t$ : time (h).

$$
S E C=E / W
$$

SEC: specific energy consumption $(\mathrm{kW} / \mathrm{h} \mathrm{kg}), W$ : water weight eliminated during drying $(\mathrm{kg})$. 


\section{Results and Discussion}

This section provides results and a discussion of the proposed control paradigm presented in the previous section. The results obtained using the proposed control parameter (PSTL) and the conventional constant air temperature (CAT) are compared. The test material in the experiment was mangosteen peel.

\subsection{Hardware and experimental setup}

Our built-in dryers ${ }^{(27)}$ using heat pump technology with an extended operating range were operated between 30 and $70{ }^{\circ} \mathrm{C}$. The system was equipped with a surface temperature sensor and a weight sensor to collect data. Figure 5 shows the installation of the mangosteen peel on the tray as the food material in the experiments.

\subsection{Drying results}

Figures 6 and 7 show drying characteristics obtained using PSTL and CAT control. PSTL control has better initial moisture transfer and a similar decrease in moisture to that of CAT control over time, which was consistent with the drying temperature effect. In Fig. 6, the drying time for PSTL control was determined for final values of around $22 \% \mathrm{RH}$ and $19 \% \mathrm{RH}$ at $50{ }^{\circ} \mathrm{C}$ in Fig. 6(a) and $60{ }^{\circ} \mathrm{C}$ in Fig. 6(b), respectively, and was less than that for CAT control. These effects yielded the result in Fig. 7 that the mass of moisture transferred from the product using PSTL control was greater than that using CAT control. Note that a greater difference between the air temperature and surface temperature of the product will result in greater moisture mass transfer.

Figure 7 shows a comparison of the two drying conditions at drying temperatures of 50 and $60{ }^{\circ} \mathrm{C}$. Initially, PSTL control has a higher drying rate than CAT control. The drying rate decreases with time. As the drying temperature decreases, the relative humidity increases, resulting in a lower mass transfer, lower moisture content, and lower drying rate. In PSTL control at $50{ }^{\circ} \mathrm{C}$, the temperature is set to lower than the air temperature at the start of the process, causing the drying rate to increase. However, at $60{ }^{\circ} \mathrm{C}$, the response curve shows a

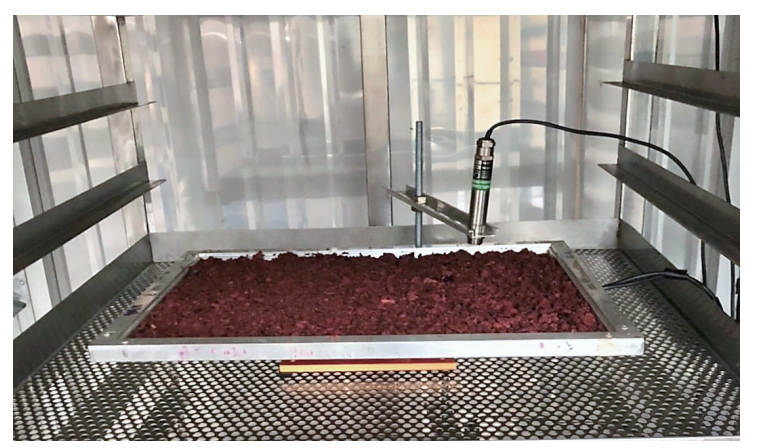

Fig. 5. (Color online) Mangosteen peel setup for drying experiment. 


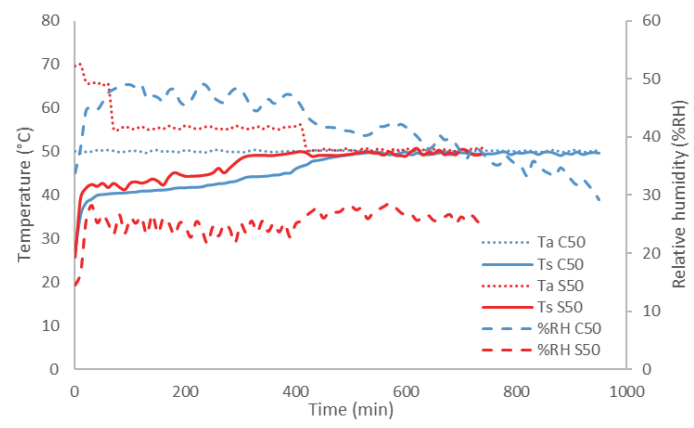

(a)

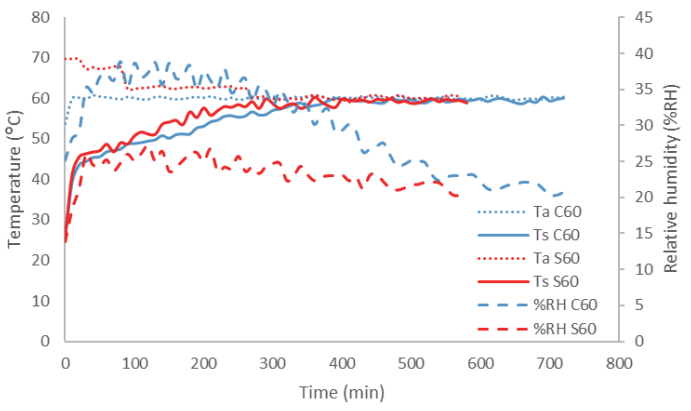

(b)

Fig. 6. (Color online) Changes in air temperature, surface temperature, and weight during drying of mangosteen peel. Note that $\mathrm{C} 50$ stands for CAT control at $50{ }^{\circ} \mathrm{C}$ and S60 stands for PSTL control at $60{ }^{\circ} \mathrm{C}$.

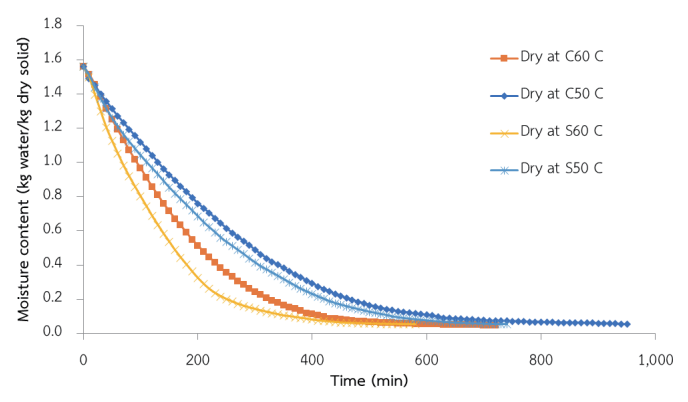

(a)

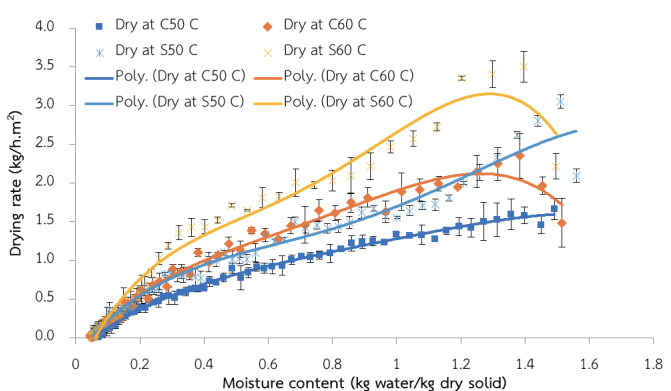

(b)

Fig. 7. (Color online) (a) Moisture content (dry base) of products per drying period and (b) drying rate per moisture content (dry base) during drying of mangosteen peel. Note that $\mathrm{C} 50$ stands for CAT control at $50{ }^{\circ} \mathrm{C}$ and S60 stands for PSTL control at $60^{\circ} \mathrm{C}$.

higher drying rate. Thus, PSTL control realized a higher drying rate than CAT control at the same temperature.

\subsection{Food quality and energy consumption}

Table 1 shows the moisture content, water activity, and color value of the powdered mangosteen peel. By comparing the percentage moisture content using the dry basis, it can be seen that the results obtained using PSTL control are only slightly lower than those obtained using CAT control, indicating no significant difference. In terms of the water activity of the product, corresponding to the relative humidity of the final air in the drying process, PSTL control provides a lower final relative humidity than CAT control. The hue angle and chroma values were in the range of 58.85-60.54. These values corresponded to brown colors. There was no significant difference in the color changes for both PSTL temperatures. However, for CAT control, there were significantly different hue angles and chroma values between drying at 50 and $60^{\circ} \mathrm{C}$. 
Table 1

Moisture content, water activity (aw), and color value of powdered mangosteen peel.

\begin{tabular}{lcccc}
\hline Condition & $\begin{array}{c}\text { \% Moisture content } \\
(\text { dry basis) }\end{array}$ & Water activity & Hue angle & Chroma \\
\hline CAT50 & $5.71 \pm 0.15^{\mathrm{ns}}$ & $0.2818 \pm 0.0033^{\mathrm{a}}$ & $58.85 \pm 0.11^{\mathrm{b}}$ & $30.57 \pm 0.18^{\mathrm{b}}$ \\
CAT60 & $5.69 \pm 0.11^{\mathrm{ns}}$ & $0.2040 \pm 0.0021^{\mathrm{c}}$ & $60.63 \pm 0.15^{\mathrm{a}}$ & $31.81 \pm 0.24^{\mathrm{a}}$ \\
PSTL50 & $5.60 \pm 0.14^{\mathrm{ns}}$ & $0.2371 \pm 0.0019^{\mathrm{b}}$ & $60.20 \pm 0.13^{\mathrm{a}}$ & $31.74 \pm 0.21^{\mathrm{a}}$ \\
PSTL60 & $5.56 \pm 0.09^{\mathrm{ns}}$ & $0.2010 \pm 0.0027^{\mathrm{d}}$ & $60.54 \pm 0.19^{\mathrm{a}}$ & $31.94 \pm 0.27^{\mathrm{a}}$ \\
\hline
\end{tabular}

Values shown in the table are mean \pm standard deviation. Different letters a-d indicate statistically significant differences $(p \leq 0.05)$, ns indicates no significant difference.

Table 2

Energy consumption analysis.

\begin{tabular}{lcc}
\hline Condition & $\begin{array}{c}\text { Energy consumption } \\
(\mathrm{kW} . \mathrm{h})\end{array}$ & $\begin{array}{c}\text { Specific energy consumption } \\
(\mathrm{kW} . \mathrm{h} / \mathrm{kg})\end{array}$ \\
\hline CAT50 & $70.93 \pm 0.85^{\mathrm{a}}$ & $3.65 \pm 0.04$ \\
CAT60 & $60.82 \pm 0.79^{\mathrm{b}}$ & $3.13 \pm 0.04$ \\
PSTL50 & $42.81 \pm 1.12^{\mathrm{c}}$ & $2.20 \pm 0.06$ \\
PSTL60 & $39.26 \pm 1.04^{\mathrm{d}}$ & $2.02 \pm 0.05$ \\
\hline
\end{tabular}

Values shown in the table are mean \pm standard deviation. Different letters a-d indicate statistically significant differences $(p \leq 0.05)$.

From Table 2, it can be seen that PSTL control can reduce the energy consumption of the process by approximately $40 \%$ due to the reduction in drying time. Consequently, the specific energy consumption is also reduced.

It is clear that the temperature sensors can be optimally used in the drying processes if they are placed to sense the maximum surface temperature of the product. In doing so, the desired product quality is achieved, and the power consumption of the proposed PSTL control is reduced compared with that of CAT control.

\section{Conclusion}

The objective of this study was to optimize the use of temperature sensors in the drying process. Appropriately placing the sensors and utilizing them to limit the surface temperature of food products helps maintain the quality of the products while reducing the energy consumption of the drying process, as demonstrated for mangosteen peel. The control algorithm uses the PSTL and time constants of the system to estimate the model reference and to monitor the parameters to be controlled. The experimental results show that the proposed method is not only effective in preserving the quality of the food, but also reduces the drying time and increases the energy efficiency compared with conventional drying methods that use room air temperature as a tracking parameter.

\section{Acknowledgments}

This study was supported in part by National Research Council of Thailand (Fiscal Year 2020). 


\section{References}

1 F. A. N. Fernandes, S. Rodrigues, C. L. Law, and A. S. Mujumdar: Food Bioprocess Technol. 4 (2011) 163. https://doi.org/10.1007/s11947-010-0323-7

2 M. K. Krokida, E. Tsami, and Z. B. Maroulis: Drying Technol. 16 (1998) 667. https://doi. org/10.1080/07373939808917429

3 C. T. Kiranoudis and N. C. Markatos: J. Food Eng. 46 (2000) 145. https://doi.org/10.1016/S0260-8774(00)000601

4 H. H. Nijhuis, H. M Torringa, S. Muresan, D. Yuksel, C. Leguijt, and W. Kloek: Trend Food Sci. Technol. 9 (1998) 13. https://doi.org/10.1016/S0924-2244(97)00007-1

5 G. O. Ondier, T. J. Siebenmorgen, and A. Mauromoustakos: J. Food Eng. 100 (2010) 545. https://doi. org/10.1016/j.jfoodeng.2010.05.004

6 S. Phatanayindee, C. Borompichaichartkul, G. Srzednicki, J. Craske, and M. Wootton: Drying Technol. 30 (2012) 1870. https://doi.org/10.1080/07373937.2012.703275

7 P. P. Lewicki: ACS Food Sci. Technol. 17 (2006) 153. https://doi.org/10.1016/j.tifs.2005.10.012

8 V. Sosle, G. S. V. Raghavan, and R. Kittler: Drying Technol. 21 (2003) 539. https://doi.org/10.1081/DRT120018461

9 I. Zlatanović, M. Komatina, and D. Antonijević: Appl. Therm. Eng. 53 (2013) 114. https://doi.org/10.1016/j. applthermaleng.2013.01.012

10 A. S. Mujumdar: Handbook of Industrial Drying (Taylor \& Francis Group, Boca Raton, 2006) 3rd ed., Chap. 1.

11 K. J. Chua, S. K. Chou, J. C. Ho, A. S. Mujumdar, and M. N. A. Hawlader: Food Bioprod. Process. 78 (2000) 72. https://doi.org/10.1205/096030800532761

12 R. Y. Jumah, A. Mujumdar, and V. G. S. Raghavan: Handbook of Industrial Drying (Taylor \& Francis Group, Boca Raton, 2006) 3rd ed., Chap. 49.

13 B. Sturm, W. C. Hofacker, and O. Hensel: Annual Int. Meeting of the ASABE (ASABE, 2009) 096219. https:// doi.org/10.13031/2013.27087

14 A.-M. Nuñez Vega, B. Sturm, and W. Hofacker: J. Food Eng. 170 (2016) 16. https://doi.org/10.1016/j. jfoodeng.2015.08.033

15 K. J. Chua and S. K Chou: ACS Food Sci. Technol. 14 (2003) 519. https://doi.org/10.1016/j.tifs.2003.07.003

16 B. Sturm, A. N. Vega, and W. C. Hofacker: Appl. Therm. Eng. 62 (2014) 455. https://doi.org/10.1016/j. applthermaleng.2013.09.056

17 S. Cernîşev: J. Food Eng. 96 (2010) 114. https://doi.org/10.1016/j.jfoodeng.2009.07.002

18 Y. Fujimoto, H Chiba, R. Okawa, and K. Toko: Sens. Mater. 27 (2015) 365. https://doi.org/10.18494/ SAM.2015.1099

19 J. Liang, J. Zhang, P. Wang, C. Liu, S. Qiu, and T. Ueda: Sens. Mater. 28 (2016) 201. https://doi.org/10.184 94SAM.2016.1281

20 Y. Sun, H. Gu, Z. Wei, and H. Xu: Sens. Mater. 30 (2018) 1947. https://doi.org/10.18494/SAM.2018.1811

21 M. A. Hannan, A. Hussain, and S. A. Samad: Sens. Mater. 23 (2011) 179. https://doi.org/10.18494/SAM.2011.694

22 M. Halimic and W. Balachandran: Proc. 1995 IEEE Int. Symp. Ind. Electron (IEEE, 1995) 786. https://doi. org/10.1109/ISIE.1995.497286

23 P. Pietrzak, M. Meller, and M. Niedźwiecki: Mech. Syst. Sig. Process. 48 (2014) 67. https://doi.org/10.1016/j. ymssp.2014.02.013

24 S. Phoungchandang and S. Saentaweesuk: Food Bioprod. Process. 89 (2011) 419. https://doi.org/10.1016/j. fbp. 2010.07.006

25 S. Eleeyah, S. Fameera, and H. Radchadaporn: J. Yala Rajabhat Univ. 7 (2012) 105. http://wb.yru.ac.th/ha ndleyru/1298

26 R. Assawarachan: TSAE 22 (2016) 28. https://li01.tci-thaijo.org/index.php/TSAEJ/article/ download/68894/56086

27 T. Pongsuttiyakorn, P. Sooraksa, and P. Pornchalermpong: Sens. Mater. 31 (2019) 2393. https://doi.org/10.18494/ SAM.2019.2347

28 S. S. Haykin: Adaptive Filter Theory (Prentice Hall, Canada, 2002) 4th ed., Chap. 10.

29 W.-L. Mao and C.-W. Hung: Sens. Mater. 30 (2018) 1691. https://doi.org/10.18494/SAM.2018.1873 


\section{About the Authors}

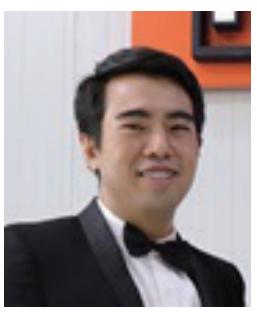

Thadchapong Pongsuttiyakorn received his B.E. and M.E. degrees from King Mongkut's Institute of Technology Ladkrabang (KMITL), Thailand, in 2010 and 2013, respectively. From 2013 to 2015, he was an employee of Address and Huntz Co., Ltd., Thailand. He is currently a doctoral candidate of the Department of Food Engineering, Faculty of Engineering, KMITL. His research interests are in drying processes, food control, food engineering, and sensors. (tpsky.7@gmail.com).

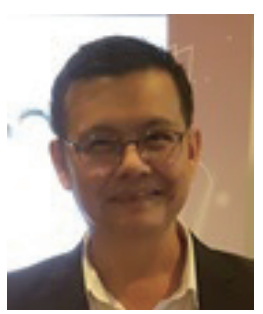

Pitikhate Sooraksa received his B.Ed. (Hons.) degree from Srinakharinwirot University, Patumwan, Thailand, in 1988 and his M.Sc. and Ph.D. degrees, both in electrical engineering, from George Washington University, Washington DC, and University of Houston, Texas, USA, in 1993 and 1996, respectively. Since 1997, he has been working at KMITL, Thailand. His current research interests are in robotics and artificial intelligence with applications. (pitikhate.so@kmitl.ac.th)

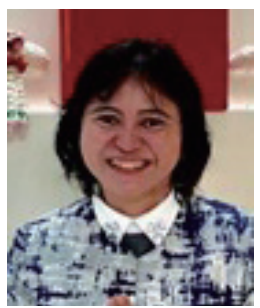

Pimpen Pornchalermpong received her B.S. and M.S. degrees from Kasetsart University, Thailand, in 1987 and 1989, respectively, and her Ph.D. degree from the Food Science and Human Nutrition (Food Science) University, Florida, USA, in 1999. Since 2010, she has been an assistant professor at KMITL, Thailand. Her research interests are in the thermal processing of food design, the development of food processing, the effect of processing on food quality, and the engineering properties of food.

(pornchaloem.food@gmail.com) 